\title{
DESAIN DAN IMPLEMENTASI SYNCHRONOUS REFERENCE FRAME- PHASE LOCKED LOOP (SRF-PLL) UNTUK TEGANGAN SATU FASE MENGGUNAKAN DSPIC30F4011
}

\author{
Muhammad Hanif Abdurrahman*), Iwan Setiawan, dan Susatyo Handoko \\ Departemen Teknik Elektro, Universitas Diponegoro \\ Jl. Prof. Sudharto, SH, Kampus UNDIP Tembalang, Semarang 50275, Indonesia \\ ${ }^{*}$ Email: mhaniifa22@gmail.com
}

\begin{abstract}
Abstrak
Fase, magnitude, dan frekuensi dari tegangan listrik merupakan informasi penting dalam pengoprasian sistem jaringan. Berdasarkan kebutuhan penerapan koneksi pembangkit dengan grid side converter (GSC), GSC harus dapat dioperasikan meski pun jaringan mengalami interferensi. Untuk mencapai tujuan tersebut, dibutuhkan metode yang dapat mendeteksi gangguan jaringan secara cepat, yaitu dengan menggunakan metode Phase Locked Loop (PLL) yang dapat menyediakan informasi tegangan jaringan. Dibandingkan dengan algoritma PLL yang lainnya, Synchronous Reference Frame-Phase Locked Loop (SRF-PLL) bisa dikatakan merupakan yang paling populer dalam penerapannya. Dalam Penelitian ini, dibuat sebuah desain untuk pengaplikasian SRF-PLL untuk tegangan satu fase menggunakan mikrokontroler 16-bit dsPIC30f4011 dengan kontroler PI, dimana kontroler PI diharapkan akan membuat sistem memiliki respon yang cepat terhadap perubahan yang terjadi, dikarenakan tujuan dari kebutuhan PLL itu sendiri, sehingga akan didapatkan hasil data tegangan jaringan berupa, magnitude, frekuensi dan fase. Hasilnya, pengkondisi sinyal dapat mengatur sinyal tegangan jaringan agar dapat terabca oleh ADC mikrokontroler, sehingga magnitude, frekuensi, dan fase dari tegangan jaringan berhasil dibaca oleh algoritma SRF-PLL yang ditampilkan pada oscilloscope dengan bantuan DAC 8bit.
\end{abstract}

Kata kunci: SRF-PLL, dsPIC30f4011, grid voltage, fase, magnitude, frekuensi

\begin{abstract}
Phase, amplitude and frequency of the utility voltage is a fundamental aspect for the design of the grid-connected inverter systems. Based on the grid connection requirements, the Grid Side Converter (GSC) should be able to operated and connected to the grid even if the grid is experiencing interference. To achieve this purposes, the GSC control system technically should have ability to detect grid disturbances quickly ie by using Phase Locked Loop (PLL) method which can provide grid voltage information. Compared to other PLL algorithms, the Synchronous Reference FramePhase Locked Loop (SRF-PLL) is likely the most popular PLL type in practice. In this final project, designed an implementation of SRF-PLL for 1 phase voltage using microcontroller dsPIC30f4011 with PI controller, which is PI controller is expected to make the system has a fast response to the changes that occur, due to the purpose of the PLL's own needs, so that will get the results of grid voltage such as magnitude, frequency and phase. As the results, the signal conditioner can adjust the grid voltage signal to be achieved by the microcontroller ADC, so that the magnitude, frequency, and phase of the grid voltage are successfully read by the SRF-PLL algorithm which displayed on the oscilloscope with 8bit DAC aid.
\end{abstract}

Keywords: SRF-PLL, dsPIC30f4011, grid voltage, phase, magnitude, frequency

\section{Pendahuluan}

Fase, magnitude, dan frekuensi dari tegangan listrik merupakan informasi penting dalam pengoprasian sistem jaringan. Pemantauan informasi tegangan pada jaringan digunakan untuk memastikan bahwa kinerja sistem jaringan sesuai dengan standar yang diinginkan, akurasi dan kecepatan deteksi fase pada tegangan listrik merupakan hal yang penting untuk memastikan pembangkitan yang benar dari sinyal referensi [1] [2].
Berdasarkan kebutuhan penerapan koneksi pembangkit dengan grid side converter (GSC), GCS harus dapat dioperasikan meski pun jaringan mengalami interferensi, misalnya pemutusan dan penurunan atau kenaikan tegangan. Untuk mencapai tujuan tersebut, dibutuhkan metode yang dapat mendeteksi gangguan jaringan secara cepat, yaitu dengan menggunakan metode PLL yang dapat menyediakan informasi tegangan jaringan [3]. Struktur Phase-locked Loop (PLL) merupakan sistem kontrol feedback yang secara otomatis menyesuaikan fase 
dari pembangkitan sinyal lokal untuk menyesuaikan fase sinyal masukan [1] [4].

Dibandingkan dengan algoritma PLL yang lainnya, SRFPLL bisa dikatakan merupakan yang paling populer dalam penerapannya. Dengan menggunakan parameter kontroler PI, variabel tegangan jaringan, seperti sudut fase, frekuensi, dan besar tegangan jaringan bisa didapatkan [3]. Iwan telah melakukan simulasi metode SRF-PLL yang dibandingkan dengan metode PLL lainnya [3]. Penelitian lainnya, A. Nicastri, juga telah dilakukan simulasi SRF-PLL 1 fase dengan berbagai metode Quadrature Signal Generator [1]. Kedua penelitian yang telah dilakukan tersebut hanya merupakan simulasi, sehingga pada Penelitian ini akan dilakukan pengaplikasian menggunakan

Dalam Penelitian ini, dibuat sebuah desain untuk pengaplikasian SRF-PLL untuk tegangan satu fase dengan menggunakan mikrokontroler 16-bit dsPIC30f401 dengan kontroler PI, dimana kontroler PI diharapkan akan membuat sistem memiliki respon yang cepat terhadap perubahan yang terjadi, dikarenakan tujuan dari kebutuhan PLL itu sendiri, sehingga akan didapatkan hasil data tegangan jaringan berupa, magnitude, frekuensi dan fase yang akan dibandingkan dengan hasil dari simulasi SRF-PLL pada Simulink matlab.

\section{Metode}

\subsection{Perancangan Perangkat Keras}

Perancangan sensor tegangan 1 fase yang dilakukan pada Penelitian ini terdiri dari 3 blok utama, yaitu blok pengkondisi tegangan, blok proses, dan blok display. Blok pengkondisi tegangan terdiri dari sumber tegangan AC 1 fase $220 \mathrm{~V}$ dan rangkaian pengkondisi sinyal. Blok proses terdiri dari sismin dsPIC30f4011 tempat berjalannya program SRF-PLL dan modul DT-I/O DAC08. Blok display terdiri dari aplikasi visual studio pada PC/Laptop sebagai penmpil data frekuensi dan tegangan jaringan dan oscilloscope sebagai penampil besar fase yang direpresentasikan dengan gelombang gergaji. Diagram blok perancangan yang dirancang pada Penelitian ini ditunjukkan pada Gambar 1.

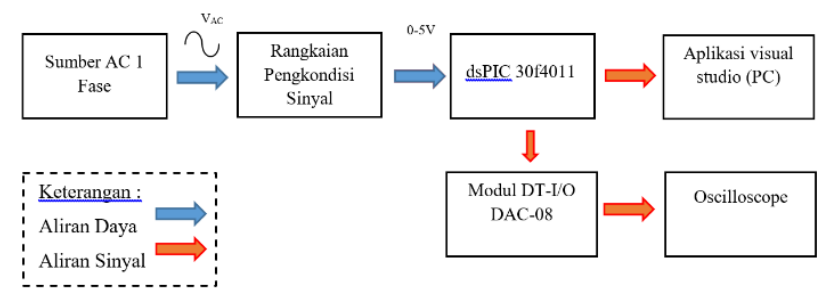

\section{Gambar 1. Diagram blok perancangan sistem}

Dari diagram blok pada Gambar 1 dapat dilihat skema alur dari alat yang akan dibuat pada Penelitian ini. Berikut spesifikasi tiap - tiap bloknya.

1. Sumber tegangan AC 1 fase digunakan untuk mensuplai rangkaian pengkondisi sinyal 1 fase.
2. Rangkaian pengkondisi sinyal digunakan untuk menurunkan tegangan input 1 fase dan mengaturnya, sehingga dapat diproses oleh mikrokontroler dsPIC30F4011.

3. Mikrokontroller 16-Bit dsPIC30f4011digunakan untuk memproses output data dari pengkondisi sinyal, antara lain melakukan pembacaan ADC, menjalankan algoritma QSG, dan algoritma SRF-PLL.

4. Komputer digunakan untuk menampilkan keluaran geombang setelah dilakukan fungsi SRF PLL menggunakan program yang dibuat dengan Visual Studio 2015. Data yang diamati dari gelombang berupa magnitude dan frekuensi dalam tegangan 1 fase tersebut.

\subsubsection{Perancangan Pengkondisi Sinyal}

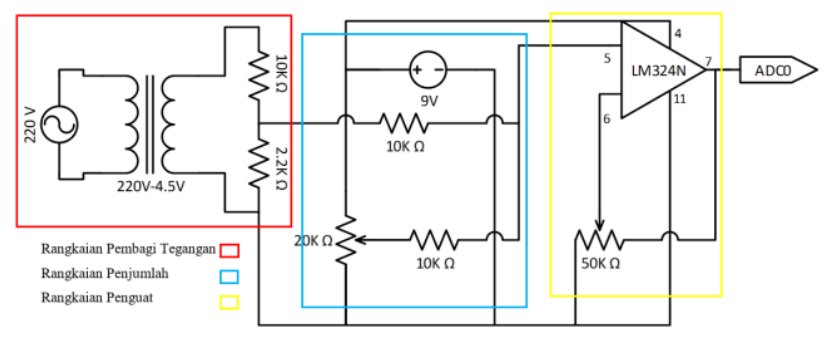

Gambar 2. Skema Rangkaian Pengkondisi Sinyal

Berdasarkan Gambar 2, sumber tegangan 1 fase 220V$230 \mathrm{~V} / 50 \mathrm{~Hz}$ dari PLN masuk ke input trafo stepdown $220 \mathrm{~V} / 0 \mathrm{~V}$ untuk diturunkan tegangannya menjadi $4,5 \mathrm{~V}$ AC, selanjutnya menuju ke blok rangkaian pembagi tegangan untuk diturunkan lagi tegangannya, sehingga saat sinyal tegangan diangkat ke atas garis nol, magnitudenya tidak $>5 \mathrm{~V}$ pada blok summer circuit, untuk keperluan mengatur posisi gelombang digunakan potensiometer $20 \mathrm{~K} \Omega$ sebagai pengatur tegangan DC yang dihasilkan, untuk nantinya mengangkat gelombang keluaran dari blok rangkaian pembagi tegangan. Yang terakhir yaitu mengatur besar magnitude gelombang menggunakan potensiometer $50 \mathrm{~K} \Omega$ yang ada pada blok gain circuit, yang terdiri dari sebuah IC LM324N yang merupakan IC op-Amp dan sebuah potensiometer $50 \mathrm{~K} \Omega$ sebagai pengatur besar kecilnya magnitude gelombang. Perlu diketahui bahwa tegangan input dari PLN dan dari trafo bisa saja berubah-ubah sehingga diperlukan rangkaian sensor yang dinamis untuk bisa selalu menghasilkan sinyal keluaran sensor sebaik mungkin.

Idealnya, tegangan $220 \mathrm{~V}$ masuk ke trafo step down dan oleh trafo diturunkan menjadi $4.5 \mathrm{~V}$ menghasilkan gelombang sinus dari tegangan -4.5 hingga $4.5 \mathrm{~V}$. $O p$ Amp LM324N akan menguatkan tegangan keluaran trafo yang kombinasikan dengan potensiometer, kita dapat mengatur gelombang tegangan keluaran sensor sesuai keinginan kita antara $0-5 \mathrm{~V}$ sinus. Kita atur tegangan minimum $0.2 \mathrm{~V}$ dan tegangan maksimum $4.8 \mathrm{~V}$. Kita atur tegangan minimum $0.2 \mathrm{~V}$ dan tegangan maksimum $4.8 \mathrm{~V}$. Pemilihan ini memberikan jarak $0.2 \mathrm{~V}$ dari batas $5 \mathrm{~V}$ 
untuk mencegah tegangan naik hingga melebihi $5 \mathrm{~V}$, karena jika melebihi $5 \mathrm{~V}$ akan mengganggu pemrosesan data pada dsPIC30F401.

\subsubsection{Alokasi Pin dsPIC30f4011}

Mikrokontroler yang digunakan dalam Penelitian ini adalah mikrokontroler dsPIC30f4011 yang berfungsi sebagai pemrosesan program SRF-PLL. DsPIC30f4011 memiliki 5 port utama yaitu PORT RB, PORT RC, PORT RD, PORT RE, dan PORT RF serta memiliki total pin berjumlah 20 pin. Pada Penelitian ini digunakan PORT RB pada pin RB7/AN7 sebagai masukan analog (ADC0) pengkondisi sinyal, PORT RF pada pin RF0-RF6 sebagai koneksi serial dan keluaran data digital yang terhubung ke modul DT-I/O DAC 8-bit (modul DAC), PORT RD pada pin RD1 sebagai control chip select $(\mathrm{A} / \mathrm{B})$ dan pin RD1 sebagai masukan write untuk modul DAC dan. Berikut merupakan skema alokasi masukan dan keluaran pin mikrokontroler dsPIC30f411 pada Gambar 3.

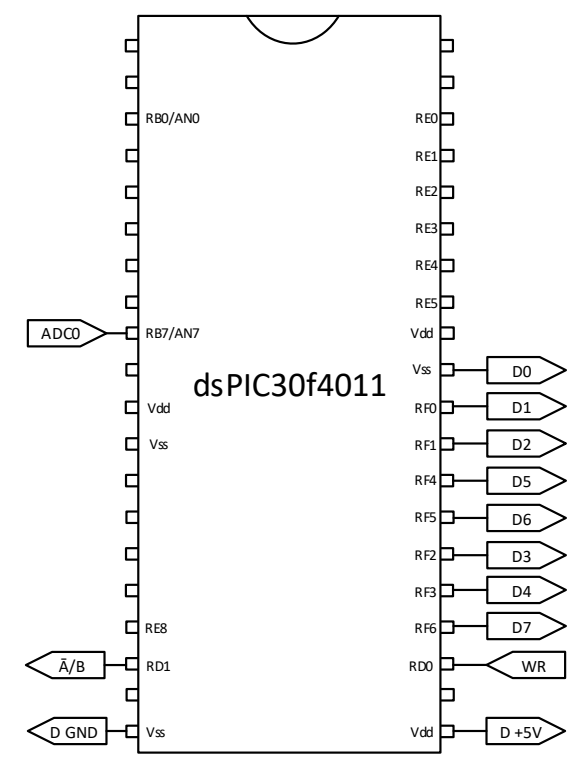

Gambar 3. Alokasi input-output mikrokontroler

\subsubsection{Alokasi Pin DAC 8bit}

Pin yang digunakan pada PORT J1 hanya pin $\overline{\mathrm{A}} / \mathrm{B}$ yang dihubungkan ke pin RD1 dsPIC30f4011 dan pin WR yang dihubungkan ke pin RD0 dsPIC30f4011 sebagai input write. Pin yang digunakan pada PORT J2 yaitu pin D0-D7, dimana pin D1-D7 dihubungkan ke pin RF0-RF6 dsPIC30f4011 sedangkan pin D0 dihubungkan ke Vss dsPIC30f4011. Yang terakhir adalah PORT J3 yang berfungsi sebagai port keluaran data analog, dimana pada port ini pin AOUT dihubungkan dengan probe channel 1 oscilloscope dan pin AGND dihubungkan dengan ground channel 1 oscilloscope, BOUT dihubungkan dengan channel 2 oscilloscope dan BGND dihubungkan dengan ground channel 2 oscilloscope. Berikut Gambar konfigurasi dan alokasi input-output modul DAC DT-I/O DAC 8-bit pada Gambar 4.

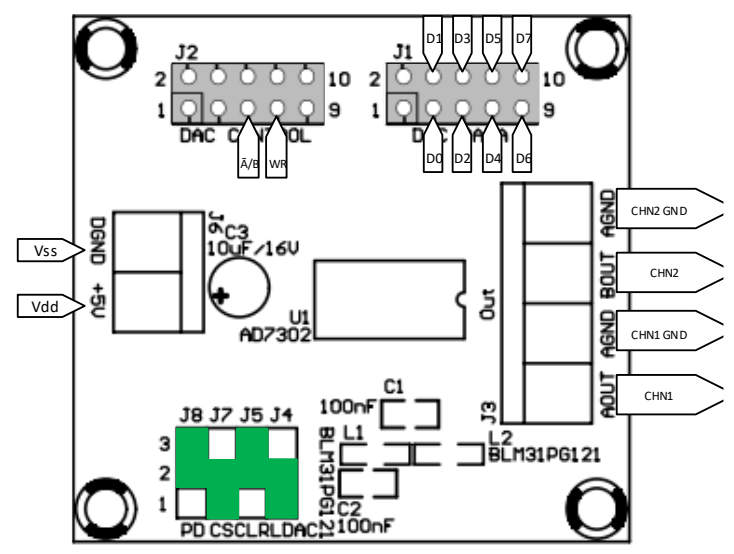

Gambar 4. Peta Input-Output Modul DAC

\subsection{Perancangan Simulasi SRF-PLL}

Pada metode SRF-PLL 1 fase input tegangan Va atau V $\alpha$ dan $\mathrm{Vb}$ atau $\mathrm{V} \beta$ yang masing-masing berbeda sudut fase sebesar $90^{\circ}$, dirubah menjadi $\mathrm{Vd}$ dan $\mathrm{Vq}$ menggunakan Park Transformation. Vd merepresentas ikan magnitude tegangan dan $\mathrm{Vq}$ menunjukan vektor dari magnitude tersebut, nilai $\mathrm{Vq}$ seharusnya mendekati nilai nol. Selanjutnya nilai $\mathrm{Vq}$ akan diberi kontrol PI untuk mendapatkan sinyal kontrol. Setelah itu keluaran sinyal kontrol akan diproses untuk mendapatkan nilai frekuensi dan fase dari jaringan sesungguhnya. Berikut ini adalah simulink sistem SRF-PLL pada Gambar 5.

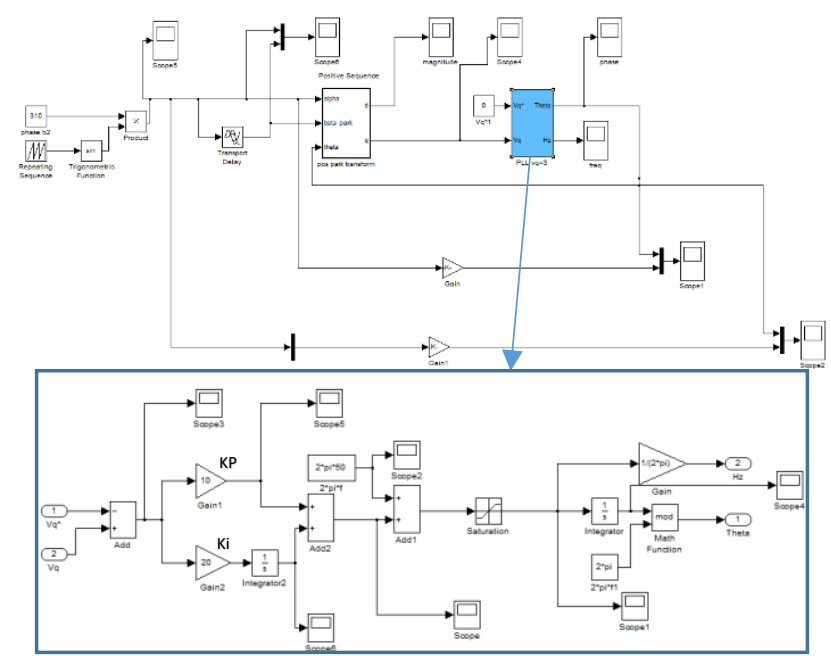

Gambar 5. Simulasi Simulink SRF-PLL

Dalam subsistem ini terlihat $\mathrm{Vq}$ hasil transformasi Park dibandingkan dengan nilai konstan $\mathrm{Vq}=0$ karena nilai $\mathrm{Vq}$ seharusnya adalah 0 . Kemudian keluaran perbandingan diberi kontroler PI. Gain 1 merupakan nilai Kp dan Gain 2 adalah Nilai Ki, keduanya diperoleh dengan cara empiris. Keluaran kontroler PI menghasilkan 
sinyal control yang kemudian ditambahkan dengan bias. Bias itu sendiri merupakan nilai omega yang bernilai $2 \pi \mathrm{f}$ dengan $\mathrm{f}=49$. Selanjutnya keluaran dari kontrol PI dan Bias akan dijumlahkan menjadi nilai omega terbaru. Untuk mendapatkan nilai frekuensi, dijumlahkan nilai sinyal kontrol dengan bias, akan menghasilkan nilai $\omega$ (omega), seperti yang kita ketahui, rumus omega adalah $2 \pi f$, maka untuk mendapatkan nilai frekuensi (f) kalikan nilai omega dengan $1 / 2 \pi$.

\subsection{Perancangan Program SRF-PLL}

Program SRF-PLL ini dimulai dengan pembacaan nilai output dari pengkondisi sinyal menggunakan fitur pembacaan nilai ADC, berikut ini adalah program pembacaan ADC:

//baca nilai ADC

SI_va_pu = ADCBUF0 $\quad / /-1: 1$

Karena memiliki tipe data signed integer (SI), Maka nilai ADC yang masuk akan disimpan menjadi -32767 sampai dengan 32767 (signed integer 15 bit). Selanjutnya adalah membuat nilai $\mathrm{V} \beta$ dengan menggunakan metode QSG, yaitu dengan cara men-delay $\mathrm{V} \alpha$ sebanyak 26 sampling. Algoritma QSG dalam program sebagai berikut:

SI_valpha_pu=SI_va_pu; $\quad / / \mathrm{v}$ alpha $\ldots . . . \mathrm{OK}$

SI_qsg_pu[0]=SI_va_pu;

for $(\mathrm{i}=26 ; \mathrm{i}>0 ; \mathrm{i}--)$

$\{$ SI_qsg_pu[i]=SI_qsg_pu[i-1]; $\}$

SI_vbeta_pu=SI_qsg_pu[27]; //v beta

Dikarenakan sistem dianggap seimbang, maka $\mathrm{Va}=\mathrm{V} \alpha$, selanjutnya pembuatan $\mathrm{V} \beta$ dengan memanfaatkan interrupt program yang berjalan setiap 0.0002 detik sekali. Karena 1 gelombang AC dari PLN berperiode 0.02 detik, maka dalam 1 periode gelombang input terjadi 100 (0.02 s/0.0002 s) kali sampling data oleh program. Sehingga program akan ditunda sebanyak 26 kali sampling untuk tundaan $1 / 4$ gelombang $\mathrm{V} \alpha$, sehingga didapatkan $\mathrm{V} \beta$ yang berbeda fase $90^{\circ}$ terhadap $\mathrm{V} \alpha$.

//---------- Updater Point Theta --------

SI_sin_theta=SIN_TABLE[(unsigned

char)(UI_theta_index $>>8)$ ];

SI_cos_theta=SIN_TABLE[(unsigned char) $($ (UI_theta_index+ UI_D_THETA_90)>>8)];

//------------ Park Transformation

SI_dumy 1=_builtin_mulss(SI_valpha_pu,SI_cos_theta) $>>15$; SI_dumy2=_builtin_mulss(SI_vbeta_pu,SI_sin_theta) $>>15$; SI_vd_pu=_Q15add(SI_dumy1,SI_dumy2); //vd

SI_dumy $1=$ _builtin_mulss(SI_vbeta_pu,SI_cos_theta) $>>15$; SI_dumy2=_builtin_mulss(SI_valpha_pu,SI_sin_theta) $>>15$; SI_vq_pu=_Q15sub(SI_dumy1,SI_dumy2); //vq

Dari program di atas didapatkan nilai magnitude yaitu SI_vd_pu. Selanjutnya mendapatkan nilai kontrol PI dari program berikut.

\author{
//--------------hitung output proporsional \\ SI_outP_pu=_builtin_mulss(SI_Kp,SI_vq_pu) $>>15$; \\ //--------------hitung output integral--------------------- \\ SI_dumy1=_builtin_mulss(SI_Ki,SI_vq_pu) $>>15$; \\ SI_out_integral_pu=_Q15add(SI_dumy1,SI_out_integral_pu);
}

SI_omega_PI_pu=_Q15add(SI_outP_pu,SI_out_integral_pu);//h itung keluaran $(\mathrm{P}+\mathrm{I})$

if(SI_omega_PI_pu<=0)SI_omega_PI_pu=0;

UI_omega_PI_pu=(unsigned int)SI_omega_PI_pu $<<1$; // x2--> $1\left(2^{\wedge} 15\right)->1\left(2^{\wedge} 16\right)$

SI_omega_PI_pu=_Q15add(SI_outP_pu,SI_out_integral_pu);//h itung keluaran $(\mathrm{P}+\mathrm{I})$

if(SI_omega_PI_pu<=0)SI_omega_PI_pu=0;

UI_omega_PI_pu=(unsigned int)SI_omega_PI_pu $<<1$; // x2--> $1\left(2^{\wedge} 15\right)->1\left(2^{\wedge} 16\right)$

UI_omega_PI_pu adalah nilai sinyal kontrol yang ada dalam sistem SRF-PLL ini. Selanjutnya didapatkan nilai frekuensi dengan program berikut.

UL_omega_pu=(unsigned long)UI_omega_PI_pu+(unsigned long)UI_OMEGA_BIAS_pu;

if(UL_omega_pu>65535)UL_omega_pu=65535;

UI_omega_pu=(unsigned int)UL_omega_pu;

Bagian terakhir dari algoritma ini adalah memperbarui nilai theta yang digunakan dalam proses penghitungan. Berikut adalah program yang digunakan.

UI_delta_theta=_builtin_muluu(UI_K_D_THETA,UI_omega $\mathrm{pu})>>16$; //(UIx $\overline{\mathrm{UI}})=$ Unsigned long Int (32 bit)

UI_theta_index=UI_theta_index+UI_delta_theta;

Selanjutnya untuk mengirimkan data-data yang telah diproses dalam SRF-PLL untuk ditampilkan pada oscilloscope melalui DAC digunakan program berikut.

write_to_DAC(1,(SI_vbeta_pu^0b1000000000000000)>>8); write_to_DAC (1,UI_theta_index $>>8)$;

//kirim vd

write_to_DAC(1,(SI_vd_pu^0b1000000000000000)>>8);

//kirim 8 msb ke DAC 8 bit

//kirim omega dan phasa

write_to_DAC(0,UI_omega_pu>>8); //kirim 8 msb ke DAC 8 bit

\section{Hasil dan Analisa}

Pengujian dilakukan pada hardware dan program yang telah dibuat, dan akan dibandingkan dengan hasil dari simulasi Simulink matlab. Pada bagian hardware, yang pertama akan dilakukan pengujian dan pembahasan mengenai pengkondisi sinyal yang berfungsi menjadikan tegangan masukan AC 1 fase $220-230 \mathrm{~V}$ menjadi sinusoidal $0-5 \mathrm{~V}$ yang dapat dibaca oleh ADC mikrokontroler serta merepresentasikan sinusoidal 1 fase. Yang kedua akan dilakukan running serangkaian program SRF-PLL pada mikrokontroler dsPIC30f4011 yang 
keluarannya akan dikirimkan ke DAC agar dapat ditampilkan pada oscilloscope. Berikut ini Table 3 yang merupakan variable penelitian yang perlu diketahui.

Tabel 1. Pengaruh konstanta waktu terhadap waktu steady state

\begin{tabular}{cc}
\hline Variabel & Nilai \\
\hline Tegangan masukan & $220-230 \mathrm{~V}$ \\
pengkondisi sinyal & \\
Tegangan masukan DC & $9-10 \mathrm{~V}$ \\
Keluaran pengkondisi sinyal & $0-5 \mathrm{~V}$ \\
Tegangan Referensi & $4.7-5 \mathrm{~V}$ \\
mikrokontroler & $310 \mathrm{~V}$ \\
Masukan magnitude pada & \\
simulasi & $49 \mathrm{~Hz}$ \\
Frekuensi bias pada program & $51 \mathrm{~Hz}$ \\
Base Frekuensi pada program & $310-325 \mathrm{~V}$ \\
Base magnitude
\end{tabular}

\subsection{Pengujian Rnagkaian Pengkondisi Sinyal}

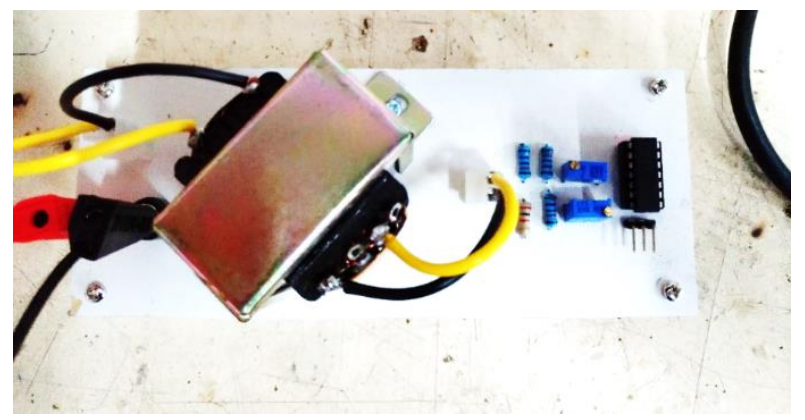

Gambar 6. Hardware Pengkondisi Sinyal

Hardware ini digunakan untuk mengatur gelombang masukan sinusoidal 1 fase dengan cara memutar salah satu atau kedua trimpot sesuai kondisi gelombang yang ada. Gambar 7 merupakan gelombang keluaran pengkondisi sinyal yang telah diatur sedemikian sehingga didapatkan keluaran gelombang seperti pada Gambar berikut.

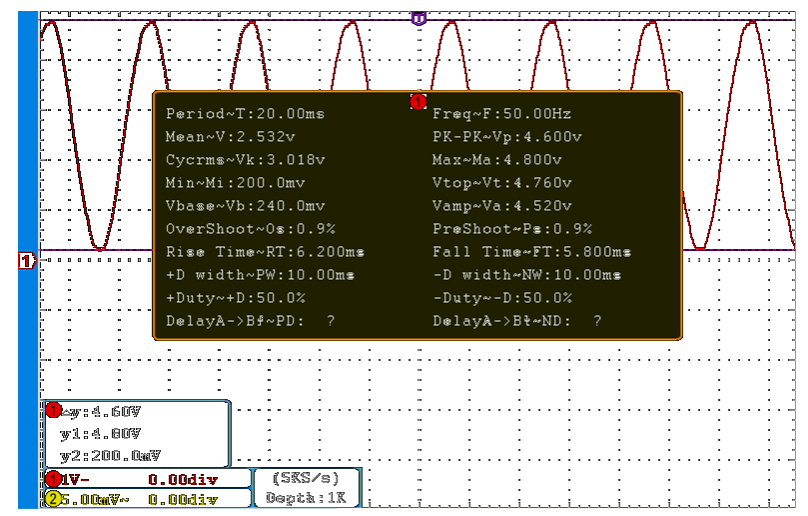

Gambar 7. Gelombang keluaran rangkaian pengkondisi sinyal (1V/div)
Terlihat nilai Vmin $=120,0 \mathrm{mV}$ dan $\mathrm{Vmax}=4,68 \mathrm{mV}$ dengan pengaturan $1 \mathrm{~V} /$ div, artinya garis tengah gelombang tegangan adalah $2,5 \mathrm{~V}$. Sebenarnya penentuan titik tengah gelombang berdasarkan pada tegangan keluaran mikrokontroler. Hasil gelombang tegangan keluaran pengkondisi sinyal ini sudah sesuai dengan gelombang tegangan pengkondisi sinyal yang diinginkan.

\subsection{Pembacaan Hasil Quadrature Signal Generator (QSG)}

Pada subbab ini, akan dilakukan pembacaan hasil QSG menggunakan metode transport delay yang hasilnya merupakan V $\beta$. Pada teorinya, agar dapat menjadi masukan yang baik bagi transformasi Park, seharusnya $\mathrm{V} \alpha$ dengan $\mathrm{V} \beta$ yang ideal berbeda fase sebesar $90^{\circ}$. Berikut hasil penerapan metode QSG pada Simulink matlab menggunakan transport delay pada masukan Va selama 0,005s yang diberikan pada Simulink matlab untuk menjadikan V $\beta$ berbeda fase $90^{\circ}$ terhadap $\mathrm{V} \alpha$., selanjutnya dibandingkan dengan hasil keluaran program.Berikut Gambar 8 dan 9 hasil yang diperoleh dari simulasi dan running program pada alat.

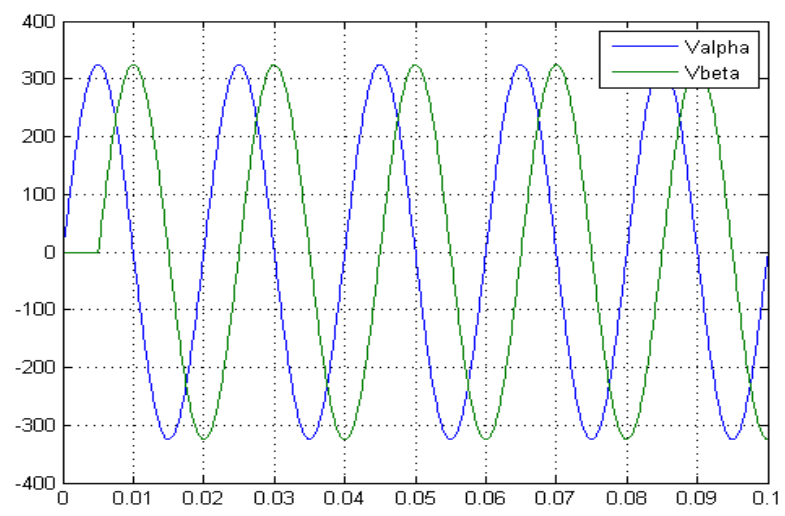

Gambar 8. Gelombang V $\alpha$ dan V $\beta$ Simulink

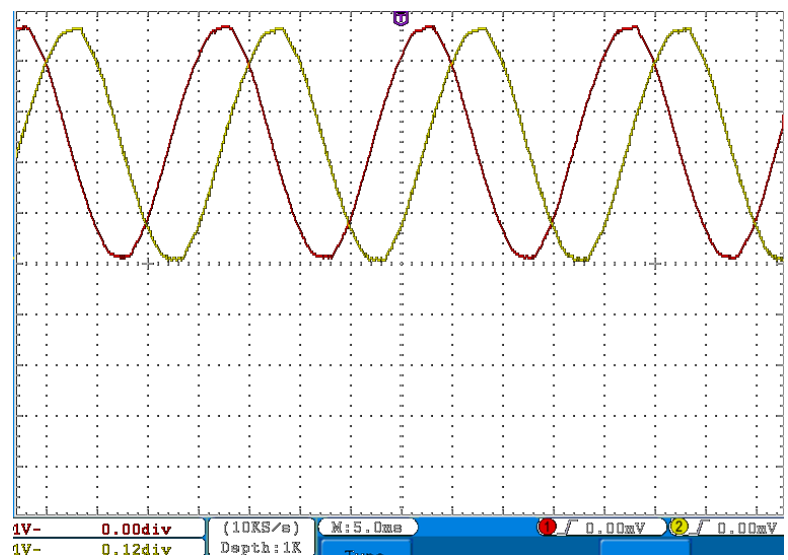

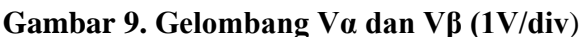

Gambar 8 dan 9 di atas merupakan gelombang V $\alpha$ dan $\mathrm{V} \beta$ hasil simulasi dan running program SRF-PLL pada alat. 
Jika dibandingkan, hasil dari running alat dengan simulasi Simulink matlab, keluaran $\mathrm{V} \alpha$ dan $\mathrm{V} \beta$ sudah sesuai dengan kondisi yang seharusnya, yaitu $\mathrm{V} \alpha$ dan $\mathrm{V} \beta$ berbeda fase $90^{\circ}$ atau bisa dibilang $\mathrm{V} \alpha$ merupakan sinusoidal dan $\mathrm{V} \beta$ merupakan gelombang cosinus.

\subsection{Pembacaan Nilai Magnitude}

Nilai magnitude (SI_vd_pu) dari sebuah tegangan bisa didapatkan merubah masukan Va menjadi $\mathrm{V} \alpha$ dan $\mathrm{V} \beta$ menggunakan algoritma QSG, selanjutnya $\mathrm{V} \alpha$ dan $\mathrm{V} \beta$ akan masuk ke transformasi Park. Hasil dari transformasi Park adalah nilai $\mathrm{Vd}$ dan $\mathrm{Vq}$ dimana $\mathrm{Vd}$ merepresentasikan nilai magnitude sedang $\mathrm{Vq}$ merepresntasikan vektor posisi tegangan tersebut.

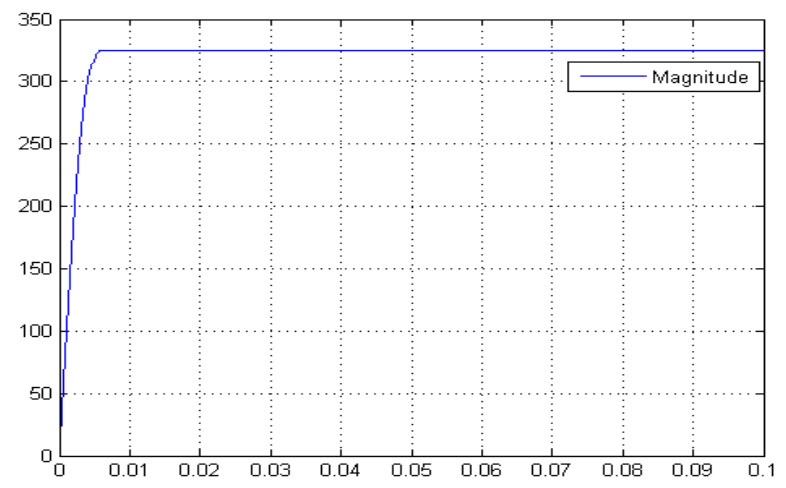

Gambar 10. Magnitude keluaran simulasi matlab

Dari Gambar 10 di atas telihat bahwa gelombang $\mathrm{Vd}$ stabil pada nilai $325 \mathrm{~V}(220 \sqrt{2})$ yang menunjukan magnitude dari tegangan 1 fase. Delay pada awal gelombang disebabkan masukan $\mathrm{V} \beta$ yang terlambat 0,005 $\mathrm{s}$ dari $\mathrm{V} \alpha$, sehingga pada gelombang $\mathrm{Vd}$ terjadi delay selama 0,005 s. hasil simulasi Simulink matlab ini selanjutnya dibandingakan dengan hasil keluaran program SRF-PLL pada alat. Gambar 11 merupakan hasil monitoring pembacaan keluaran magnitude.

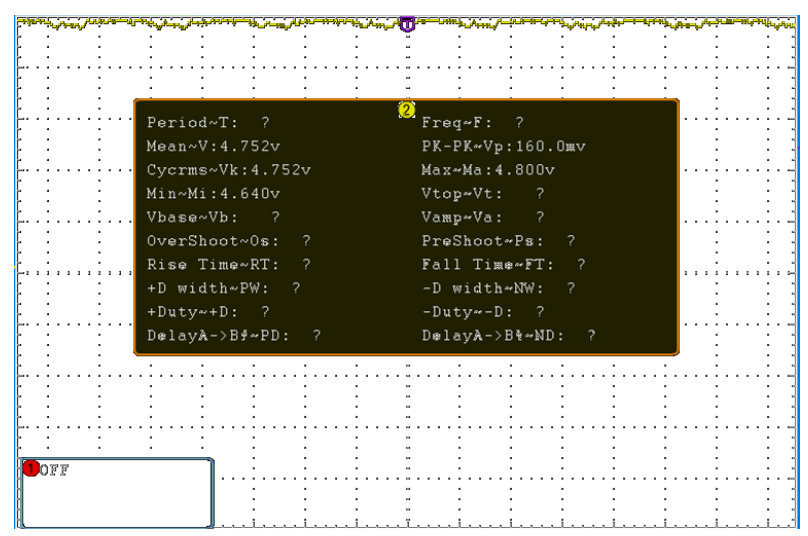

Gambar 11. Magnitude Hasil Pembacaan SRF-PLL (1V/div)
Dalam perhitungan yang benar, seharusnya nilai magnitude yang ideal berkisar pada nilai 310 - 325. Dari data pada Gambar 11, Vrms DAC yang terbaca adalah $4,752 \mathrm{~V}$, jika dihitung menggunakan rumus $N=$ $\frac{\text { Vout } D A C}{\text { Vref }} x$ (base) dengan $\mathrm{N}$ merupakan nilai sebenarnya dan base merupakan nilai actual tertinggi yang mungkin, maka nilai magnitude yang sebenarnya adalah $\pm 315,2 \mathrm{~V}$. dari data yang didapat bias disimpulkan bahwa antara pengujian dengan simulasi sudah hampir sesuai, selisih yang terjadi disebabkan perubahan nilai Vref.

\subsection{Pembacaan Nilai Frekuensi}

Pada diagram blok Simulink SRF-PLL terdapat masukan bias berupa omega bias ( $\omega$ bias $=2 \pi f)$, dimana omega bias akan dijumlahkan dengan keluaran kontrol PI, dari omega bias ini kita bisa dapatkan nilai frekeunsi dengan mengalikan hasil dari penjumlahan omega bias dengan keluaran kontrol PI yang dinamakan "omega (UI_omega_pu)" dikalikan dengan $1 / 2 \pi$ sehingga didapatkan nilai frekuensi. Berikut hasil gelombang frekuensi dari simulasi Simulink matlab pada Gambar 12.

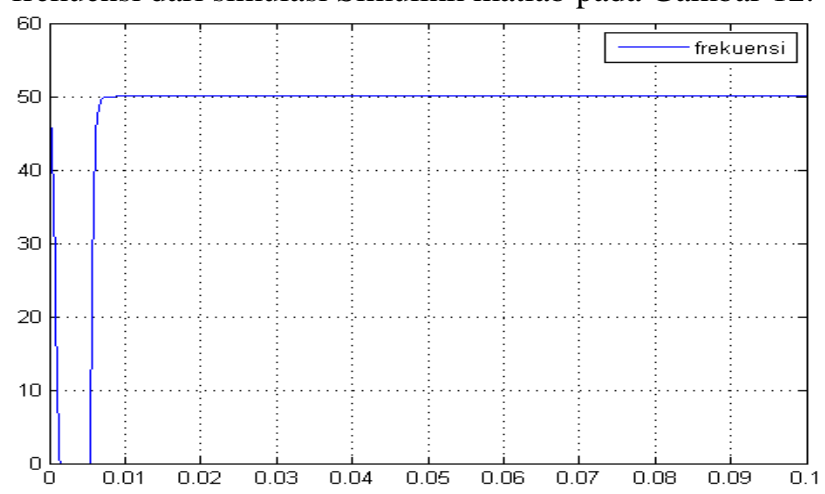

Gambar 12. Frekuensi Keluaran Simulasi Simulink Matlab

Pada Gambar 12 terlihat bahwa nilai frekuensi stabil pada garis 50, artinya nilai frekuensi yang terukur pada hasil simulasi sudah stabil pada nilai $50 \mathrm{~Hz}$, drop yang terjadi selama $0,005 \mathrm{~s}$ pada awal gelombang disebabkan delay selama $0,005 \mathrm{~s}$ pada masukan V $\beta$. Selanjutnya dibandingkan dengan hasil pengujian program pada alat yang ditunjukan pada Gambar 13.

Berdasarkan Gambar 12, terlihat bahwa nilai keluaran DAC yang terbaca berosilasi pada nilai Vrms $=4,736 \mathrm{~V}$. Untuk mendapatkan nilai sebenarnya dari frekuensi ini digunakan rumus $N=\frac{\text { Vout } D A C}{\text { Vref }} x$ (base) dengan $\mathrm{N}$ merupakan nilai frejuensi sebenarnya dan base merupakan nilai frekuensi terbesar yang mungkin $=51$. Selanjutnya diperoleh hasil perhitungan $\pm 49,3 \mathrm{~Hz}$, nilai tersebut merupakan nilai frekuensi hasil pembacaan pada alat. Hasil perhitungan yang telah dilakukan sudah mendekati nilai ideal yaitu $50 \mathrm{~Hz}$. Gelombang hasil pembacaan juga sudah sesuai dengan yang teorinya, yaitu nilai frekuensi = 
nilai omega bias dan akan naik nilainya jika terdapat sinyal kontrol PI.

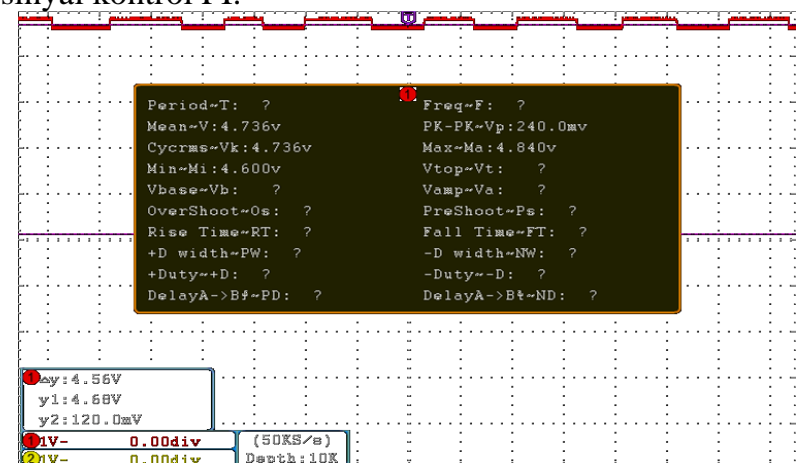

Gambar 12. Monitoring pembacaan frekuensi (1V/div)

\subsection{Pembacaan Fase}

Berdasarkan Gambar 13, kita dapat lihat bahwa nilai fase berbentuk gelombang gergaji dengan nilai $0-6$. Nilai $0-$ 6 ini merepresentasikan nilai 0 - $2 \pi$ yang merupakan besar theta $(\theta)$ sinusoidal keluaran pengkondisi sinyal.

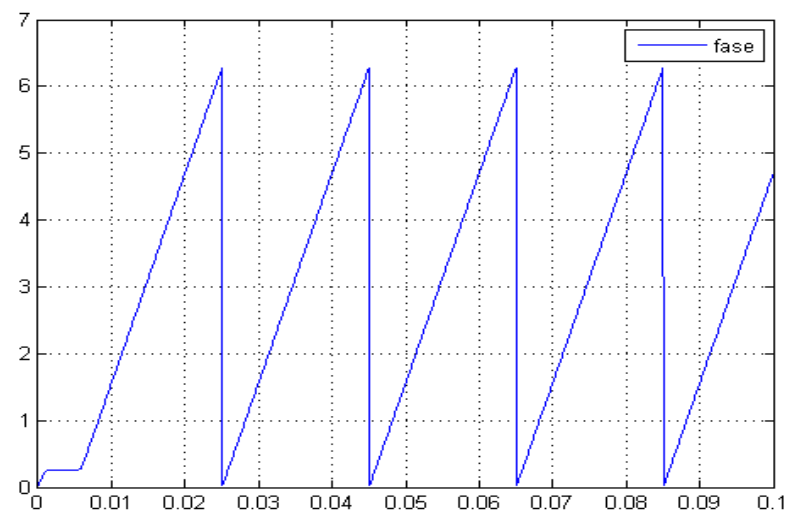

Gambar 13. Gelombang fase dan output sensor dari simulasi matlab

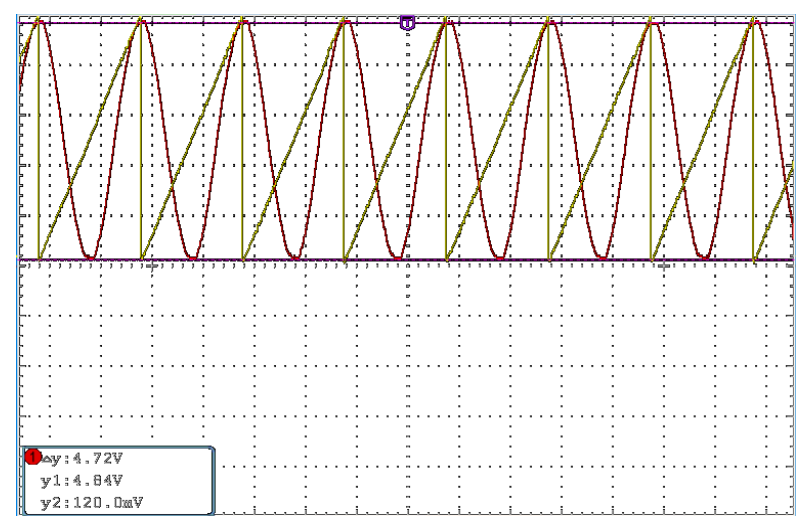

Gambar 14. Perbandingan fase pada gelombang keluaran rangkaian sensor tegangan (1V/div)

Berdasarkan Gambar 14 dapat kita lihat bahwa antara gelombang masukan Va dengan gelombang fase sudah memiliki tren yang sama, sehingga bias kita anggap bahwa kedua geombang tersebut memiliki fase yang sama.

\section{Kesimpulan}

Berdasarkan perancangan, pengujian dan analisa yang telah dilakukan maka dapat dibuat kesimpulan Synchronous Reference Frame-Phase Locked Loop (SRFPLL) satu fasa telah berhasil direalisasikan menggunakan mikrokontroler dsPIC30f4011 dan dapat menghasilkan data magnitude, frekuensi dan gelombang fase representasi dari keluaran pengkondisi sinya. Pengkondisi sinyal dapat mengatur tegangan jaringan agar dapat menjadi sinyal masukan ADC sesuai kebutuhan dsPIC30F4011. Penerapan Quadrature Signal Generator menggunakan transport delay sudah berhasil menghasilkan gelombang Vbeta yang berbeda fase sebesar $90^{\circ}$ dengan gelombang Valpha.

Pembacaan magnitude hasil keluaran mikrokontroler sudah masuk dalam keriteria sesuai dengan teori yang ada, yaitu pada nilai $315,2 \mathrm{~V}$ dengan Vout DAC $=4,752 \mathrm{~V}$. Pembacaan frekuensi hasil keluaran alat dari pengujian program pada alat terbaca pada Vrms $=4,736 \mathrm{~V}$, dengan nilai sebenarnya $\pm 49,3 \mathrm{~Hz}$., metode SRF-PLL ini juga sudah dapat mengeluarkan gelombang fase sesuai dengan simulasi pada Simulink matlab dengan tren yang sesuai dengan sinusoidal Va.

\section{Referensi}

[1]. A. Nicastri and A. Nagliero, "Comparison and Evaluating of The PLL Techniques for The Design of the grid -connected inverter systems," pp. 1-2, 2010.

[2]. B. F, T. R, L. M and T. A V, "overview of control and grid synchronization for distributed power generation systems," IEEE Trans, on Ind Electronics, vol. 53, 2006.

[3]. I. Setiawan, M. Facta, A. Priyadi and M. H. Purnomo, "Comparison of Three Popular PLL Schemes Under Balanced and Unbalanced Grid Voltage Condition," p. 2, 2016.

[4]. H. G. C and H. J. C, "Phase-locked loop techniques," A Survey, IEEE Trans. On Ind.Electronic, vol. 43, 1996.

[5] G. H. R and W. A, "Analisis Energi Terselamatkan Pada Penyulang Bangli PT. PLN (Persero) Area Bali Timur dengan Beroprasinya PLTS Kayubihi," Majalah Ilmiah Teknologi Elektro, vol. 15, p. 1, 2016.

[6]. I. Setiawan, M. Facta, A. Priyadi and M. H. Purnomo, "Estimator Parameter Tegangan Jaringan Tiga Fasa Berbasis D-SOGI PLL," vol. 16, p. 1, 2017.

[7]. S. S. M, L. B. M, C. F. B. J, C. R. P and B. W. C, "Performance evaluation of PLL algorithms for single-phase grid-connected systems," IEEE IAS, 2004.

[8]. M. F. H. and N. , "Phase Quadrature Signal Generator Having a Variable Phase Shift Network," United States Patent, 1999. 